\title{
Nutritional status, brain development and scholastic achievement of Chilean high-school graduates from high and low intellectual quotient and socio-economic status
}

\author{
Daniza M. Ivanovic ${ }^{1 *}$, Boris P. Leiva ${ }^{1}$, Hernán T. Pérez ${ }^{1}$, Atilio F. Almagià ${ }^{2}$, Triana D. Toro ${ }^{2}$, María \\ Soledad C. Urrutia ${ }^{3}$, Nélida B. Inzunza ${ }^{4}$ and Enrique O. Bosch ${ }^{5}$ \\ ${ }^{1}$ University of Chile, Institute of Nutrition and Food Technology (INTA), Human and Clinical Nutrition Area, Santiago, Chile \\ ${ }^{2}$ Catholic University of Valparaíso, Laboratory of Physical Anthropology, Valparaíso, Chile \\ ${ }^{3}$ Ministry of Education, Santiago, Chile \\ ${ }^{4}$ Adventist University of Chile (Camino Tanilvoro S/N, Chillán, Chile) Loma Linda University, Loma Linda \\ California 92350, USA \\ ${ }^{5}$ Department of Magnetic Resonance Imaging Service, German Clinic of Santiago, Santiago, Chile
}

(Received 7 August 2000 - Revised 4 June 2001 - Accepted 31 August 2001)

\begin{abstract}
The objective of the present study was to investigate the inter-relationships between nutritional status (past and current nutrition), brain development, and scholastic achievement (SA) of Chilean high-school graduates from high and low intellectual quotient (IQ) and socio-economic status (SES) (mean age 18.0 (SD 0.9) years). Results showed that independently of SES, highschool graduates with similar IQ have similar nutritional, brain development and SA variables. Multiple regression analysis between child IQ (dependent variable) and age, sex, SES, brain volume $(\mathrm{BV})$, undernutrition during the first year of life, paternal and maternal IQ (independent variables) revealed that maternal IQ $(P<0 \cdot 0001)$, BV $(P<0.0387)$ and severe undernutrition during the first year of life $(P<0 \cdot 0486)$, were the independent variables with the greatest explanatory power for child IQ variance $\left(r^{2} 0 \cdot 707\right)$, without interaction with age, sex or SES. Child IQ $(P<0 \cdot 0001)$ was the only independent variable that explained both SA variance $\left(r^{2}\right.$ $0 \cdot 848)$ and academic aptitude test variance $\left(r^{2} 0 \cdot 876\right)$ without interaction with age, sex or SES. These results confirm the hypotheses formulated for this study that: (1) independently of SES, high-school graduates with similar IQ have similar variables of nutritional status, brain development and SA; (2) past nutritional status, brain development, child IQ and SA are strongly and significantly inter-related. These findings are relevant in explaining the complex interactions between variables that affect IQ and SA and can be useful for nutritional and educational planning.
\end{abstract}

Nutrition assessment: Brain: Education: Learning: Intelligence: Socio-economic factors

Findings of previous studies carried out by us confirmed that in Chilean school-age children, the head circumference is the most important anthropometric indicator associated with school achievement and intellectual ability (Ivanovic et al. 1989a, 1996, 2000a; Toro et al. 1998).

The head circumference (HC) is a physical index of both past nutrition and brain development (Rumsey \& Rapoport, 1983) and in paediatrics, it is a routine measurement to assess brain development since micro- and macrocephaly are considered reliable indicators of brain pathology (Menkes, 1995). It has been defined as the most sensitive anthropometric index of prolonged undernutrition during infancy, associated with intellectual impairment (Stoch \& Smythe, 1963, 1967, 1976; Winick \& Rosso, 1969a; Stoch et al. 1982; Ivanovic, 1996; Ivanovic et al. 2000b; Leiva et al. 2001). Malnutrition alters brain development and intelligence by interfering with overall health as well as with the child's energy level, rate of motor development and

\footnotetext{
Abbreviations: AAT, academic aptitude test; BV, brain volume; IQ, intellectual quotient; HC, head circumference; SA, scholastic achievement; SES, socioeconomic stratum; WAIS-R, Wechsler intelligence scale for adults - revised.

* Corresponding author: Professor Daniza M. Ivanovic, present address Avda. Macul 5540, PO Box 138-11, Santiago, Chile, fax +56 22214030 , email inta8@abello.dic.uchile.cl
} 
growth; poverty and deprivation exacerbate these negative effects, specially when mothers have lower schooling levels (Brown \& Pollitt, 1996; Ivanovic et al. 2000b).

Intelligence is influenced by genetic and environmental factors. Model fitting analyses in twins of the combined intellectual quotient (IQ) kinship correlations result in heritability estimates of approximately 0.50 , shared environmental influences of $0 \cdot 20$ and $0 \cdot 30$, the balance of variance being explained by non-shared environmental effects and measurement error (McGue \& Bouchard, 1998). Other studies converge on a heritability estimate between 0.60 and 0.80 for IQ and estimates of common environmental influence from the same studies are near zero (Bouchard, 1998). Human genome research enabled the first steps toward a molecular understanding of cognitive function confirming that there are numerous genes on the $\mathrm{X}$ chromosome affecting intelligence (Gecz \& Mulley, 2000). Studies of twins reared together and studies of unrelated individuals reared together yield sizable estimates of common family environmental influence in childhood, but also demonstrate that this influence dissipates with age and approaches zero in adulthood; in fact, twin studies of the major special mental abilities (verbal, spatial, perceptual speed and accuracy, memory) yield heritability estimates of about 0.50 and modest estimates of common environmental influence (Bouchard, 1998). Between environmental factors, the positive impact of parental IQ (specially maternal) on children's intelligence had been underlined and may be related more to the quality of the stimulation of the child, which in conditions of poverty is strongly limited by both their lower schooling levels and intelligence (Nelson \& Deutschberger, 1970; Melhuish et al. 1990; Carter et al. 1992; Duncan et al. 1994; Smith et al. 1996; Sandiford et al. 1997; Crandell \& Hobson, 1999).

The relationship between brain size and intelligence has been noted for some time (Broca, 1861; Galton, 1888). In the 20th century, a positive and significant correlation between $\mathrm{HC}$ and brain size and intelligence has been reported by several investigators, suggesting that differences in human brain size are relevant in explaining differences in intelligence, although genetic and environmental factors might also affect these inter-relationships (Nelson \& Deutschberger, 1970; Van Valen, 1974; Fisch et al. 1976; Susanne, 1979; Hack \& Breslau, 1986; Ounsted et al. 1988; Desch et al. 1990; Hack et al. 1991; Johnson,
1991; Willerman et al. 1991; Andreasen et al. 1993; Jensen \& Johnson, 1994; Reiss et al. 1996; Botting et al. 1998; Strauss \& Dietz, 1998; Ivanovic et al. 1995a, 2000a,b,c; Rushton, 2000; Rushton \& Ankney, 1996, 2000; Vernon et al. 2000; Wickett et al. 2000). Some of these studies have concluded that head size at 1 year of age is a good predictor of later intelligence (Nelson \& Deutschberger, 1970; Fisch et al. 1976; Botting et al. 1998). However, the absence of a correlation between brain measurements or $\mathrm{HC}$ and intelligence has been reported in studies of monozygotic twins or sisters (Tramo et al. 1998; Schoenemann et al. 2000). However, recent findings in a magnetic resonance imaging study on size variations in the human brains of twins found a positive correlation between brain size and IQ (Pennington et al. 2000).

The objective of the present study was to investigate the inter-relationships between nutritional status (past and current nutrition), brain development, and scholastic achievement of Chilean high-school graduates (in whom physical growth and intellectual development processes are consolidated) with high or low IQ and socio-economic stratum (SES). The aim was to test the hypotheses that: (1) independently of SES, high school graduates with similar IQ have similar variables of nutritional status, brain development and scholastic achievement (SA); (2) past nutritional status, brain development, intelligence and SA are significantly inter-related.

\section{Material and methods \\ Subjects and sample}

The sample was chosen from 1817 school-age children, the total high-school graduate population who attended public and private schools in the richest and the poorest counties of the Chile's Metropolitan region, according to the UNICEF classification (United Nations International Children's Emergency Fund, 1994). The final sample consisted of ninety-six right-handed high-school graduate students born at term (mean age 18.0 (SD 0.9) years) who had no history of alcoholism, or symptoms of brain damage, epilepsy, or heart disease and whose mothers had no history of smoking, alcoholism or drug intake before and during pregnancy. IQ, (Wechsler intelligence scale for adults - revised, WAIS-R), SES and sex were considered for sample selection. The

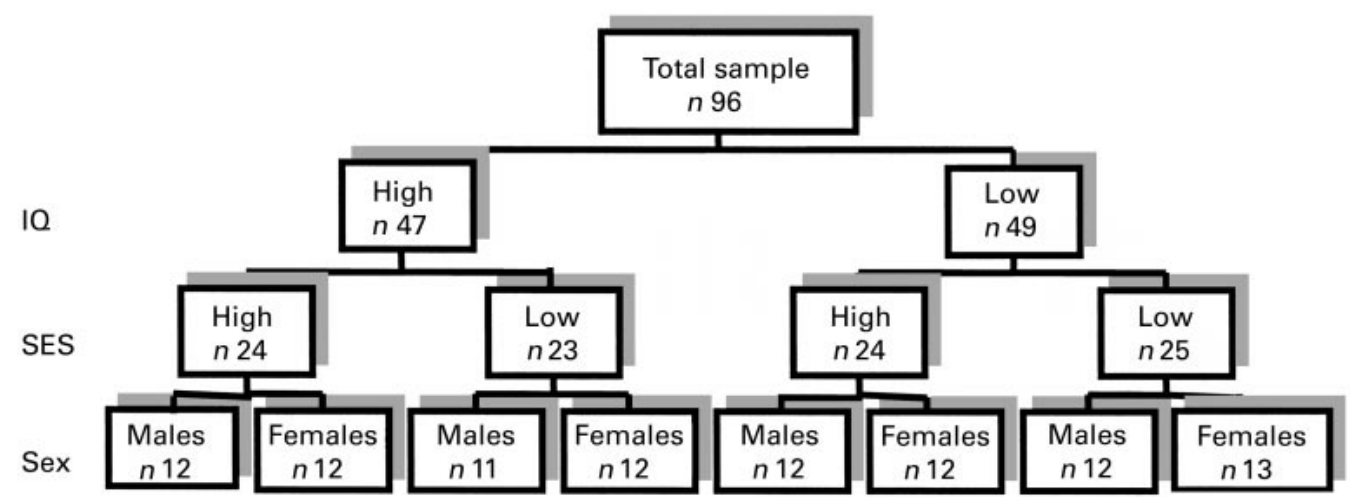

Fig. 1. Description of the sample by school-age children by intellectual quotient (IQ), socio-economic stratum (SES) and sex. 
same proportion of school-age children according to IQ (high and low) (1:1), SES (high and low) (1:1) and sex (1:1) was finally chosen (Fig. 1). A comparative study of two groups of Chilean high-school graduates was carried out: Group 1, (High IQ, $\geq 120$ WAIS-R) and Group 2 (low IQ, $<100$ WAIS-R). The total IQ of the school-age children from Group 1 (125.4 (SD 5.5), $n$ 47) was significantly higher than those from Group 2 (91.4 (SD 6.8), $n$ 49) $(t$ 26.934, $P<0.0001)$ and this was observed for verbal and non-verbal IQ. IQ (total, verbal and non-verbal) did not differ by sex in both IQ level and SES. This study was approved by the Committee on Ethics in Studies in Humans of the Institute of Nutrition and Food Technology (INTA), University of Chile.

\section{Socio-economic stratum}

SES was evaluated by applying the modified Graffar method adapted for Chilean urban population that considers items such as schooling, job held by the head of the household, characteristics of the house (building materials, ownership status, water supply, sewerage and ownership of durable goods) (Alvarez et al. 1985). This scale classifies a population into six SES: 1, high; 2, medium-high; 3, medium; 4, medium-low; 5, low; 6 , extreme poverty. In the present study, only high $(1+2)$ and low $(4+5+6)$ SES were considered because they represent extreme SES conditions.

\section{Anthropometric measurements}

Anthropometric measurements were assessed at the school by the first author of the present study on both the students and their parents, through standardised procedures (Jelliffe, 1966; Gibson, 1990). Weight was measured in a platform beam balance with an accuracy of $100 \mathrm{~g}$. Height was determined with a vertical rod with a measuring scale of $2 \mathrm{~m}$ high and with an accuracy of $0.5 \mathrm{~cm}$. When measuring height, the subject stands straight looking ahead, with Frankfurt plane horizontal, with shoulders blades, buttocks, and heels almost together touching measurement board, arms at sides, legs straight, knees together and feet flat (Gibson, 1990). Weight-for-age Z-scores and height-for-age Z-scores were not considered, since most of the subjects were $>18$ years old and WHO tables (World Health Organization, 1980) cannot be applied. The BMI (weight/ height ${ }^{2}$ ) was calculated according to Garrow (1981). HC was measured with a narrow (less than $1 \mathrm{~cm}$ wide), flexible, non-stretch tape made of fibreglass and with an accuracy of $0 \cdot 1 \mathrm{~cm}$. The head was steadied and the greatest $\mathrm{HC}$ measured, by placing the tape firmly round the frontal bones just superior to the supra-orbital ridges, passing it round the head at the same level on each side and laying it over the maximum occipital prominence at the back. HC values were compared with the tables of Roche et al. (1987) and were expressed as Z-scores. HC absolute values were adjusted by body height. Arm circumference $(\mathrm{cm})$ was measured in the midpoint of right upper arm hanging relaxed, halfway between the acromial process of the scapula and the olecranon process of the ulna. Triceps skin-fold thickness (mm) was measured with a Lange skinfold caliper, P/N
300919 (Cambridge Scientific Industries, Cambridge, MD, USA), having a pressure of $10 \mathrm{~g} / \mathrm{mm}^{2}$, and which was calibrated before measuring each subject using a gauge block, P/N 100613 (Cambridge Scientific Industries). The measurement was taken over the triceps muscle halfway between the elbow and the acromial process of the scapula, with the skinfold parallel to the longitudinal axis of the upper arm (Frisancho, 1990). Percentages of adequacy to the median of arm circumference-for-age, triceps skinfold thickness-for-age, arm muscle area-for-age and arm fat area-for-age were calculated using data from Frisancho (1981). All the instruments were verified before to measure each subject (Jelliffe, 1966; Gibson, 1990). Birth weight was used as an index of prenatal nutrition, HC Z-score and $\%$ arm muscle-for-age, served as indicators of postnatal nutrition and the BMI was used as an index of current nutritional status. Parents were interviewed to obtain information about the child's previous nutritional diseases, especially undernutrition at an early age. As these subjects had been assessed for severe undernutrition during the first year of life, parents had been given a copy of the child's clinical chart. This clinical chart from the Nutritional Recovery Centre when the child was hospitalised during the first year of life, was required for parents to accredit the magnitude of undernutrition. This was defined as weight Z-score $<-2$ SD according to WHO tables (World Health Organization, 1980). When the undernourished children were admitted to the Nutritional Recovery Centre during the first year of life, all of them had weight $Z$-score values $<-2$ $\mathrm{SD}$, height $\mathrm{Z}$-score values $<-1 \mathrm{SD}$ and weight-for-height Z-score values $<-2$ SD according to WHO tables (World Health Organization, 1980). These data were complemented with those obtained from the births register at the Registry Office.

\section{Intellectual quotient}

IQ (total, verbal and non-verbal) was assessed by means of the WAIS-R in both children and their parents (Wechsler, 1981). WAIS-R consists of a set of six verbal and five nonverbal subtests that are individually administered, requiring about $1.5 \mathrm{~h}$, and yields an age-corrected estimate of IQ. Measurements in parents (fathers, mean age 48.9 (SD 7.6), range 37.5-73.9 years, and mothers, mean age 45.9 (SD $5 \cdot 8$ ), range $36 \cdot 4-60 \cdot 3$ years) were carried out at the school. To avoid examiner bias, the WAIS-R was administered separately to the father, the mother and the child in quiet rooms, on the same day and at the same time, by a team of educational psychologists specially trained for this type of study. Before each item, clear explanations were provided by the psychologist to each member of the family, in order to clarify the problem to be solved. Mid-parent IQ was also calculated.

\section{Scholastic achievement test}

SA was evaluated through standard Spanish language and mathematics tests. Content validity was based on the fact that the test was designed taking into consideration the objectives pursued by the curricular programmes of the Ministry of Education (Chile Ministerio de Educación 
Pública, 1996). The number of items tested were: fifty-one for language and sixty-five for mathematics. A pilot test was carried out in 160 school-age children during which reliability was determined applying the Spearman-Brown correlation, scores being 0.92 and 0.97 for language and mathematics, respectively, when comparing paired and unpaired items (Guilford \& Fruchter, 1984). Item-test consistency for each item was measured by Pearson correlation, scoring values greater than 0.30 in all of them (Guilford \& Fruchter, 1984). Results were expressed as percentage of achievement in overall results $(\mathrm{SA}=$ (language score + mathematics score) $/ 116 \times 100$ ), as well as language absolute language and mathematics scores. In addition, the academic aptitude test (AAT; applied nationally in Chile), total, verbal and mathematics scores were considered.

\section{Brain development study}

Brain development was evaluated at the German Clinic of Santiago, Chile, by magnetic resonance imaging. Using the lowest margin of the cerebellum in a midsagittal view to align the first axial (horizontal) magnetic resonance imaging slice, eighteen mixed-weighted images (spin-echo pulse sequence with a time of repetition (TR) of $2000 \mathrm{~ms}$ and a time of echo (TE) of $30 \mathrm{~ms}$ ) were obtained from a Signa MRI General Electric unit (General Electric Medical System, Milwaukee, Wisconsin, USA) with a field strength of $1.5 \mathrm{~T}$. All images were $5 \mathrm{~mm}$ thick and separated by $2.5 \mathrm{~mm}$. Each image was $256 \times 256$ pixels with 256 levels of grey. The magnetic resonance imaging tape was read into a visual analog scale (VAS) computer and the image analysed after removing identifying information. Analyses were carried out by a trained specialist without foreknowledge of IQ or sex. For each slice, a Roberts gradient traced the boundary of the scalp by outlining large-intensity differences between adjacent pixels. All grey-scale intensity values of $<96$ within this boundary were converted to zero. This deleted the skull, most of the meninges, and the interhemispheric fissure; other brain membranes were deleted manually with a cursor. The computer then counted all pixels with non-zero grey scale values for brain size in each slice, their summed value serving as the index for overall brain size. Cortex thickness data, brain volume (BV), absolute and adjusted for body height, corpus callosum length (absolute and adjusted for BV (corpus callosum length/BV)), thickness of genu, body and splenium (absolute and adjusted for corpus callosum length) (Matano \& Nakano, 1998), the presence of neuronal migration disorders, qualitative and quantitative evaluation of white matter, cortical and basal subarachnoid space and ventricular system size were assessed. At present, there is no meaningful basis for the comparison of brain sizes within and between racial groups and sexes; the control for body size across racial groups (and sexes) is rendered difficult because bodies do not just differ only in height and weight (Peters et al. 1998).

\section{Statistical analysis}

Results are expressed as mean values and standard deviations. Data were processed using the Statistical Analysis System (SAS) package (SAS Introductory Guide Statistics (1983); SAS Institute Inc., Cary, NC, USA). Statistical analysis included variance tests (PROC ANOVA) to determine significant differences between the groups and Scheffé's test was used for comparison of means. Pearson correlation coefficients (PROC CORR) were calculated in order to decide if intercorrelated variables may be included as predictor variables. Multiple regression (PROC GLM, General Linear Models procedure, error type III) was used to establish the explanatory power of the independent variables on IQ, SA and AAT variance, that were considered as dependent variables (as continuous variables) separately in three different statistical models. Chi-squared test $\left(\chi^{2}\right)$ (PROC FREQ) was used to determine significant differences between the categorical variables (Guilford \& Fruchter, 1984).

\section{Results}

The mean age of the total sample was 18.0 (SD 0.9) years. School-age children belonging to Group 2 were significantly older (18.4 (SD 1.0) years, $n$ 49) than those from Group 1 (17.6 (SD 0.4) years, $n$ 47) $(t 5.0515, P<0.0001)$ without significant differences by SES and sex. In this respect, in children from Group 2 - low SES had been presented for a significantly higher number of years $(0 \cdot 8(\operatorname{SD} 0 \cdot 6), n 25)$ than for their peers from high SES (0.5 (SD 0.7), $n$ 24) and for those from Group 1 of both high SES $(0 \cdot 0(\operatorname{SD} 0 \cdot 2), n 24)$ and low SES (0.0 (SD 0.2), $n$ 23) ( F11.85, P<0.0001).

In public schools, $67 \cdot 1 \%$ of school-age children belonged to low SES and, in private schools, $96.2 \%$ belonged to high SES $\left(\chi_{0}^{2}(1 \mathrm{df})=30 \cdot 382>\chi_{\mathrm{t}}^{2}(1 \mathrm{df}) 0.001=10 \cdot 827\right)$. As regards to IQ, in public schools $65.7 \%$ presented low IQ and in private schools $88.5 \%$ registered high IQ $\left(\chi_{0}^{2}(1 \mathrm{df})=22 \cdot 267>\chi_{\mathrm{t}}^{2}(1 \mathrm{df}) 0 \cdot 001=10 \cdot 827\right)$.

Table 1 shows parental IQ (total, verbal and non-verbal) by IQ group and SES. In the high SES, paternal IQ, whether total, verbal or non-verbal, did not differ significantly between both IQ groups, but Group 1- high SES, is a more homogeneous group due to their low IQ variance. In Group 2- low SES, paternal IQ (total, verbal and non-verbal) was significantly lower compared with their peers from the other subgroups of the sample $(P<0.0001)$. Mothers, however, exhibited different characteristics. In Group 1- high SES, maternal total IQ was significantly higher than in the other groups of the sample; in Group 1- low SES, maternal total IQ was significantly higher compared with those from Group 2 of both SES $(P<0 \cdot 0001)$. In Group 1, maternal verbal and non-verbal IQ did not show differences between the SES, although it was significantly higher than in those of Group 2 in both SES. Mothers from Group 2 that belonged to the low SES presented the lowest IQ values of the parental sample. Mid-parent IQ (total, verbal and nonverbal) was significantly higher in Group 1- high SES, compared with the other subgroups of the sample; Group 2low SES, however, showed the lowest mid-parent IQ values of the sample $(P<0 \cdot 0001)$. Mid-parent IQ (total, verbal and non-verbal) from Group 2- high SES, did not differ significantly from their peers from Group 1- low SES. No 
Table 1. Parental intellectual quotient (IQ) score by IQ group and socio-economic stratum (SES)†

(Mean values and standard deviations)

\begin{tabular}{|c|c|c|c|c|c|c|c|c|c|}
\hline & \multicolumn{4}{|c|}{ Group 1 (high IQ) } & \multicolumn{4}{|c|}{ Group 2 (low IQ) } & \multirow[b]{3}{*}{$F$} \\
\hline & \multicolumn{2}{|c|}{ High SES (n 24) } & \multicolumn{2}{|c|}{ Low SES ( $n$ 23) } & \multicolumn{2}{|c|}{ High SES (n 24) } & \multicolumn{2}{|c|}{ Low SES ( $n$ 25) } & \\
\hline & Mean & SD & Mean & SD & Mean & SD & Mean & SD & \\
\hline \multicolumn{10}{|l|}{ Paternal IQ } \\
\hline Total & $120 \cdot 8^{a}$ & 7.0 & $101 \cdot 3^{\mathrm{b}}$ & 11.0 & $115 \cdot 1^{\mathrm{a}}$ & $13 \cdot 8$ & $88.0^{c}$ & $12 \cdot 2$ & $29 \cdot 76^{\star \star \star \star}$ \\
\hline Verbal & $122 \cdot 8^{\mathrm{a}}$ & $6 \cdot 6$ & $103 \cdot 4^{\mathrm{b}}$ & $11 \cdot 1$ & $116 \cdot 6^{\mathrm{a}}$ & 14.8 & $87 \cdot 8^{\mathrm{C}}$ & $12 \cdot 6$ & $31 \cdot 33^{\star \star \star \star}$ \\
\hline Non-verbal & $115 \cdot 8^{\mathrm{a}}$ & 10.6 & $98.4^{\mathrm{b}}$ & 11.6 & $111 \cdot 4^{\mathrm{a}}$ & $12 \cdot 8$ & $89 \cdot 6^{c}$ & 11.4 & $17 \cdot 93^{\star \star \star \star}$ \\
\hline \multicolumn{10}{|l|}{ Maternal IQ } \\
\hline Total & $115 \cdot 6^{a}$ & $9 \cdot 7$ & $107 \cdot 2^{b}$ & 11.6 & $93.9^{c}$ & $12 \cdot 4$ & $79 \cdot 2^{d}$ & $11 \cdot 8$ & $43 \cdot 67^{\star \star \star *}$ \\
\hline Verbal & $115 \cdot 3^{\mathrm{a}}$ & $11 \cdot 4$ & $110 \cdot 0^{\mathrm{a}}$ & $11 \cdot 8$ & $94 \cdot 8^{\mathrm{b}}$ & $12 \cdot 2$ & $81 \cdot 4^{\mathrm{C}}$ & $11 \cdot 8$ & $36 \cdot 33^{\star \star \star \star}$ \\
\hline Non-verbal & $109 \cdot 8^{a}$ & $7 \cdot 8$ & $103 \cdot 6^{\mathrm{a}}$ & $11 \cdot 7$ & $93 \cdot 4^{\mathrm{b}}$ & 13.0 & $79 \cdot 8^{c}$ & $13 \cdot 2$ & $26 \cdot 47^{\star \star \star \star *}$ \\
\hline \multicolumn{10}{|l|}{ Mid-parent IQ } \\
\hline Total & $117 \cdot 8^{\mathrm{a}}$ & $6 \cdot 3$ & $103 \cdot 9^{b}$ & $10 \cdot 3$ & $103 \cdot 1^{\mathrm{b}}$ & $10 \cdot 0$ & $84 \cdot 9^{c}$ & $9 \cdot 1$ & $39 \cdot 61^{* * * *}$ \\
\hline Verbal & $119 \cdot 5^{\mathrm{a}}$ & 7.0 & $106 \cdot 1^{\mathrm{b}}$ & $10 \cdot 3$ & $104.6^{\mathrm{b}}$ & $9 \cdot 3$ & $86 \cdot 1^{\mathrm{c}}$ & 8.5 & $42.95^{\star \star \star \star}$ \\
\hline Non-verbal & $113 \cdot 2^{\mathrm{a}}$ & $6 \cdot 4$ & $101 \cdot 0^{\mathrm{b}}$ & $9 \cdot 8$ & $100 \cdot 8^{\mathrm{b}}$ & $10 \cdot 4$ & $85 \cdot 7^{c}$ & 9.5 & $27 \cdot 30^{\star \star \star \star}$ \\
\hline
\end{tabular}

a,b,c,dMean values within a row with unlike superscript letters were significantly different (Scheffé's test, $P<0.05$ ).

†For details of subjects and procedures, see pp. 82-83.

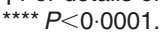

difference by sex was found in paternal, maternal or midparent IQ by IQ group and SES.

School-age children from Group 1 of both SES achieved significantly higher SA, language, mathematics and AAT scores in comparison with their Group 2 peers $(P<0 \cdot 0001)$ and this was observed independently of sex. School-age children of the low SES from Group 2 attained percentages of achievement significantly lower $(22.9 \%)$ in the SAtest (approximately one-third) than those from Group 1 of both SES $(76 \%)$ and in AAT, the score was approximately onehalf (Group 2- low SES and Group 1- high SES scored 383 and 718 respectively; $P<0.0001)$. In each IQ group, in the SAtest scores, no significant differences were found in relation to SES. In Group 2, low SES school-age children attained the lowest percentage of achievement in the sample; this was also significantly lower than their high-SES peers for language and AAT scores both verbal and mathematics $(P<0 \cdot 0001)$.

Severe undernutrition during the first year of life affected $64 \%$ of school-age children from Group 2 belonging to low SES. Nutritional status in relation to IQ group and SES is summarised in Table 2. Birth weight was significantly lower in low SES school-age children from Group 2 in comparison with the other groups of the sample $(P<0 \cdot 01)$. HC Z-scores were significantly higher in school-age children from Group 1 than their peers from Group 2, without significant differences by SES in each IQ group. BMI and brachial anthropometric variables did not differ in the study sample. In each IQ group and SES, no significant differences were found in the nutritional status variables by sex.

Table 3 shows some brain development variables according to IQ group, SES and sex. Males from Group 1,

Table 2. Nutritional status by intellectual quotient (IQ) group and socio-economic stratum (SES)†

(Mean values and standard deviations)

\begin{tabular}{|c|c|c|c|c|c|c|c|c|c|}
\hline & \multicolumn{4}{|c|}{ Group 1 (high IQ) } & \multicolumn{4}{|c|}{ Group 2 (low IQ) } & \multirow[b]{3}{*}{$F$} \\
\hline & \multicolumn{2}{|c|}{ High SES ( $n$ 24) } & \multicolumn{2}{|c|}{ Low SES ( $n$ 23) } & \multicolumn{2}{|c|}{ High SES ( $n$ 24) } & \multicolumn{2}{|c|}{ Low SES ( $n$ 25) } & \\
\hline & Mean & SD & Mean & SD & Mean & SD & Mean & SD & \\
\hline \multicolumn{10}{|c|}{ Prenatal nutritional background } \\
\hline Birth weight $(\mathrm{g})$ & $3186 \cdot 0^{\mathrm{a}}$ & $698 \cdot 7$ & $3267 \cdot 4^{a}$ & $452 \cdot 7$ & $3230 \cdot 0^{a}$ & $508 \cdot 3$ & $2752^{\mathrm{b}}$ & $397 \cdot 3$ & $5 \cdot 12^{\star \star}$ \\
\hline \multicolumn{10}{|c|}{ Postnatal nutritional background } \\
\hline HC Z-score & $0.39^{a}$ & 0.93 & $0 \cdot 15^{a}$ & 1.05 & $-0.48^{\mathrm{b}}$ & $1 \cdot 10$ & $-0.91^{\mathrm{b}}$ & 1.00 & $8.08^{\star \star \star \star}$ \\
\hline \multicolumn{10}{|l|}{ Present nutritional status } \\
\hline BMI (weight $/$ height $^{2}$ ) & $22 \cdot 1$ & $2 \cdot 8$ & $22 \cdot 2$ & $2 \cdot 0$ & $22 \cdot 2$ & 3.0 & $23 \cdot 0$ & $3 \cdot 8$ & 0.49 \\
\hline \multicolumn{10}{|c|}{ Brachial anthropometric variables } \\
\hline$\% \mathrm{AC} / \mathrm{A}$ & $96 \cdot 4$ & $9 \cdot 6$ & $96 \cdot 1$ & 8.7 & $95 \cdot 7$ & $12 \cdot 1$ & $97 \cdot 4$ & $16 \cdot 3$ & 0.09 \\
\hline$\%$ TST/A & $108 \cdot 0$ & $41 \cdot 2$ & $118 \cdot 4$ & $62 \cdot 2$ & $114 \cdot 8$ & $40 \cdot 6$ & $109 \cdot 2$ & $49 \cdot 2$ & 0.23 \\
\hline$\%$ AMA/A & 92.4 & 18.0 & $89 \cdot 2$ & $15 \cdot 9$ & 88.9 & $17 \cdot 7$ & $94 \cdot 1$ & $26 \cdot 4$ & 0.39 \\
\hline$\%$ AFA $/ A$ & $105 \cdot 8$ & $45 \cdot 2$ & $115 \cdot 1$ & $59 \cdot 6$ & $112 \cdot 7$ & $51 \cdot 2$ & $109 \cdot 6$ & $60 \cdot 4$ & 0.13 \\
\hline
\end{tabular}

$\mathrm{HC}$, head circumference; AC/A arm circumference-for-age; TST/A, triceps skinfold thickness-for-age; AMA/A, arm muscle area-for-age; AFA/A, arm fat area-forage.

a,b Mean values within a row with unlike superscript letters were significantly different (Scheffé's test, $P<0.05)$.

† For details of subjects and procedures, see pp. 82-83.

${ }^{\star *} P<0.01,{ }^{* * * *} P<0.0001$. 
Table 3. Brain development variables by intellectual quotient (IQ) group, socio-economic stratum (SES) and sex† (Mean values and standard deviations)

\begin{tabular}{|c|c|c|c|c|c|c|c|c|c|}
\hline & \multicolumn{4}{|c|}{ Group 1 (high IQ) } & \multicolumn{4}{|c|}{ Group 2 (low IQ) } & \multirow[b]{3}{*}{$F$} \\
\hline & \multicolumn{2}{|c|}{ High SES } & \multicolumn{2}{|c|}{ Low SES } & \multicolumn{2}{|c|}{ High SES } & \multicolumn{2}{|c|}{ Low SES } & \\
\hline & Mean & SD & Mean & SD & Mean & SD & Mean & SD & \\
\hline Males $(n)$ & 12 & & 11 & & 12 & & 12 & & \\
\hline \multicolumn{10}{|l|}{ CC } \\
\hline CC length (mm) & 73.5 & $4 \cdot 6$ & $71 \cdot 0$ & 4.4 & $70 \cdot 8$ & $4 \cdot 8$ & $70 \cdot 6$ & 5.4 & 0.96 \\
\hline Genu thickness (mm) & $11 \cdot 6$ & 1.6 & $11 \cdot 7$ & $2 \cdot 2$ & $11 \cdot 3$ & 1.0 & $10 \cdot 8$ & 1.8 & 0.81 \\
\hline Body thickness (mm) & $6 \cdot 6^{a}$ & 0.6 & $6 \cdot 0^{\mathrm{ab}}$ & 0.9 & $6 \cdot 5^{\mathrm{a}}$ & 0.8 & $5 \cdot 6^{\mathrm{b}}$ & 0.9 & 3.63 * \\
\hline Splenium thickness (mm) & 11.9 & $1 \cdot 6$ & $11 \cdot 4$ & 1.9 & 11.5 & $1 \cdot 2$ & $10 \cdot 6$ & 1.3 & $1 \cdot 38$ \\
\hline Absolute BV $\left(\mathrm{cm}^{3}\right)$ & $1551 \cdot 6^{a}$ & $63 \cdot 7$ & $1544 \cdot 5^{\mathrm{a}}$ & $109 \cdot 7$ & $1420 \cdot 9^{b}$ & $122 \cdot 6$ & $1409 \cdot 5^{\mathrm{b}}$ & $129 \cdot 3$ & $5 \cdot 82$ ** \\
\hline Biparietal diameter (mm) & $131 \cdot 8$ & 4.9 & $134 \cdot 2$ & 8.4 & $130 \cdot 0$ & $6 \cdot 4$ & $134 \cdot 0$ & $6 \cdot 5$ & 1.02 \\
\hline Anteroposterior diameter $(\mathrm{mm})$ & $167 \cdot 9^{\mathrm{a}}$ & $5 \cdot 2$ & $166 \cdot 4^{a b}$ & $6 \cdot 3$ & $163 \cdot 0^{\mathrm{ab}}$ & $6 \cdot 8$ & $161 \cdot 2^{b}$ & $6 \cdot 8$ & 2.83 * \\
\hline Females $(n)$ & 12 & & 12 & & 12 & & 13 & & \\
\hline \multicolumn{10}{|l|}{$\mathrm{CC}$} \\
\hline CC length (mm) & $70 \cdot 0$ & $5 \cdot 6$ & $73 \cdot 2$ & $5 \cdot 2$ & $70 \cdot 4$ & $3 \cdot 8$ & $69 \cdot 4$ & 4.4 & 1.52 \\
\hline Genu thickness (mm) & $10 \cdot 4$ & 1.8 & $11 \cdot 2$ & 1.6 & $10 \cdot 8$ & 1.2 & $11 \cdot 3$ & 1.6 & 0.79 \\
\hline Body thickness (mm) & $6 \cdot 3$ & $0 \cdot 8$ & $6 \cdot 5$ & 0.6 & $6 \cdot 6$ & 0.6 & 6.4 & $1 \cdot 0$ & 0.38 \\
\hline Splenium thickness (mm) & $10 \cdot 8$ & $2 \cdot 0$ & 11.5 & 1.6 & $11 \cdot 8$ & 1.5 & $11 \cdot 2$ & 1.2 & 0.87 \\
\hline Absolute BV $\left(\mathrm{cm}^{3}\right)$ & $1434 \cdot 2^{\mathrm{a}}$ & $86 \cdot 7$ & $1403 \cdot 4^{a}$ & $99 \cdot 1$ & $1381 \cdot 2^{a b}$ & $96 \cdot 8$ & $1361 \cdot 4^{\mathrm{b}}$ & 64.0 & $2 \cdot 88^{\star}$ \\
\hline Biparietal diameter $(\mathrm{mm})$ & $129 \cdot 0^{\mathrm{ab}}$ & $5 \cdot 1$ & $129 \cdot 8^{\mathrm{ab}}$ & $7 \cdot 2$ & $125 \cdot 6^{\mathrm{a}}$ & $4 \cdot 2$ & $133 \cdot 6^{b}$ & $6 \cdot 0$ & $4 \cdot 11^{*}$ \\
\hline Anteroposterior diameter $(\mathrm{mm})$ & 163.7 & $7 \cdot 2$ & $162 \cdot 8$ & $5 \cdot 4$ & $161 \cdot 0$ & $5 \cdot 0$ & $159 \cdot 8$ & 4.4 & 1.20 \\
\hline
\end{tabular}

CC, corpus callosum; BV, brain volume.

a,b Mean values within a row with unlike superscript letters were significantly different (Scheffé's test, $P<0.05$ ).

${ }^{\star} P<0.05,{ }^{\star *} P<0.01$.

†For details of subjects and procedures, see pp. 82-83.

had, in general, higher values for corpus callosum variables and with the exception of corpus callosum body thickness $(P<0.05)$ differences were not significant. Males from Group 2 - low SES, had the lowest corpus callosum body thickness values but without significant differences from their peers from Group 1- low SES; however, in this latter subgroup, values did not differ significantly from their peers from high SES of both IQ groups. Despite the fact that the correlations between BV and height (males $r 0 \cdot 143$, NS and females $r 0.321, P<0.05$ ) were very low, BV was adjusted for body height. BV values, both absolute and adjusted for height, were very similar; for this reason, only absolute BV values are shown in Table 3. In males, height was significant lower in the low SES of Group 2, (165.8 (SD 4.9) cm) compared with their peers from high SES (175.1 (SD 5.7) $\mathrm{cm})$ and with those from Group 1 from high SES (171.5 (SD $3 \cdot 5) \mathrm{cm}$ ) and low SES $(171 \cdot 3($ SD $5 \cdot 7) \mathrm{cm})(F 5 \cdot 84, P<0 \cdot 01)$. In the females, the mean height of the sample was $159 \cdot 4$ (SD $6 \cdot 1) \mathrm{cm}$ without significant differences according to IQ group and SES ( $F 2 \cdot 73$, NS). Independently of SES, males from Group 1 had both an absolute BV $(P<0 \cdot 01)$ or adjusted $\mathrm{BV}(F 5 \cdot 21, P<0 \cdot 01)$ significantly higher than Group 2 . The

Table 4. Multiple regression analysis table of school-age children intellectual quotient (IQ) (dependent variable) and most relevant variables (independent variables) ${ }^{\star} \dagger \ddagger$

\begin{tabular}{lcccc}
\hline Variable & Estimate & T for HO: variable=0 & $\operatorname{Pr}>[\mathrm{T}]$ & SE of estimate \\
\hline Intercept & 69.28704459 & 1.19 & 0.2373 & 58.00576803 \\
Age & -4.12496046 & -1.75 & 0.0860 & 2.36054007 \\
Sex & -5.76922019 & -1.87 & 0.0667 & 3.08465879 \\
$\quad$ Males & 0.00000000 & - & - & - \\
$\quad$ Females & & -1.38 & 0.1740 & 4.10302272 \\
SES & -5.64974256 & - & - & - \\
$\quad$ High & 0.00000000 & 2.12 & 0.0387 & 0.01497587 \\
$\quad$ Low & 0.03170842 & 2.04 & 0.0486 & 0.00541318 \\
Absolute BV & 0.01104290 & - & - & - \\
Undernutrition & 0.00000000 & 1.33 & 0.1889 & 0.14244773 \\
$\quad$ Yes & 0.18944937 & 5.00 & 0.0001 & 0.11077876 \\
$\quad$ No & 0.55416723 & & &
\end{tabular}

SES, socio-economic stratum; BV, brain volume; T, Student's $t$ test; HO, null hypothesis; Pr, probability. *For details of subjects and procedures, see pp. 82-83

† Statistical Analysis Systems (SAS Institute Inc., Cary, NC, USA), PROC GLM error type III.

$¥$ Model $r^{2} 0.707$; Root MSE (standard deviation of the dependent variable (IQ)) 10.75210573; Model $F$ value $19 \cdot 34, P<0 \cdot 0001$. 
anteroposterior diameter was significantly greater in males from Group 1 of both SES but these values were not different from the high SES of Group 2; in the low SES of Group 2, values only differed significantly from the high SES of Group 1. Males of the low SES from Group 2 had an absolute BV $142 \cdot 1 \mathrm{~cm}^{3}$, lower than those of the high SES from Group $1(P<0 \cdot 01)$, while among the females this difference was $72 \cdot 8 \mathrm{~cm}^{3} \quad(P<0 \cdot 05)$. Females from the low SES of Group 2 had the lowest values for both absolute BV $(P<0 \cdot 05)$ or adjusted BV $(F 2 \cdot 81, P<0 \cdot 05)$ compared with their peers from the other subgroups of the sample. Females from Group 2 that belonged to the low SES also had a significantly greater biparietal diameter compared with their peers of the high SES, but these values did not differ significantly from both SES of Group $1(P<0 \cdot 05)$. No significant differences were found for corpus callosum and the anteroposterior diameter. Cortex thickness in the frontal, parietal, temporal and occipital lobules was $4 \mathrm{~mm}$ in both sexes, without significant differences when compared by IQ group and SES. In low SES males from Group 2, two subjects had abnormal amounts of white matter and one case had a slight, non-specific diffuse brain atrophy.

Multiple regression analysis between child IQ as continuous variable (dependent variable) and age, sex, SES, BV (absolute or adjusted), undernutrition, paternal and maternal IQ (independent variables), the most relevant variables associated with child IQ (Table 4) confirms that maternal IQ $(P<0.0001)$, absolute BV (or adjusted) $(P<0.0387)$ and undernutrition during the first year of life $(P<0.0486)$ were the independent variables with the greatest explanatory power for child IQ variance $\left(r^{2}\right.$ 0.707) without interaction with age, sex or SES.

When SA was considered as the dependent variable (Table 5), and age, sex, SES, BV (absolute or adjusted), undernutrition, child, paternal and maternal IQ, child IQ was the only independent variable that explained SA variance $(P<0.0001)\left(r^{2} 0 \cdot 848\right)$ without interaction with age, sex or SES. The multiple regression analysis between the dependent variable AAT (Table 6), and age, sex, SES, BV (absolute or adjusted), undernutrition, child, paternal and maternal IQ, the most relevant variables associated with AAT (independent variables), revealed that child IQ, $(P<0 \cdot 0001)$ was the only independent variable that explains AAT variance $\left(r^{2} 0 \cdot 876\right)$. No significant interaction with age, sex or SES was found in the statistical model. Undernutrition during the first year of life was the only independent variable that explained BV (absolute or adjusted) variance $\left(F 7 \cdot 16, P<0 \cdot 0088 ; r^{2} 0 \cdot 124\right)$. When $\mathrm{BV}$ (absolute or adjusted) was replaced by $\mathrm{HC} \mathrm{Z}$-score in the statistical model, a similar percentage of explanation for child IQ, SA and AAT variances was observed.

\section{Discussion}

These results confirm that independently of SES and sex, high-school graduates with the highest IQ have significantly higher values for parental IQ, birth weight, HC, BV, SA and AAT than their peers with the lowest IQ. In children with high IQ we did not find significant differences in relation to SES in birth weight, HC, BV, SA and AAT. In children with low IQ, $64 \%$ of those belonging to low SES had been undernourished and had significantly lower birth weights compared with their peers from the high SES. However, comparing both SES, no significant differences were observed for the decreased HC, BV and SA. This could indicate that similar IQ could imply similar values for $\mathrm{HC}$, BV and SA. Furthermore, independently of SES and sex, school-age children with low IQ, were approximately 1 year older than those with high IQ. This fact could reveal a greater school delay in children with decreased IQ, parental IQ, HC, BV, SA and AAT, with a high incidence of undernutrition in the low SES and who mainly attended public school (Ivanovic et al. 2000b). In consequence, a greater proportion of children with the highest IQ and SES

Table 5. Multiple regression analysis table between school-age children scholastic achievement (dependent variable) and most relevant variables (independent variables)* $† \ddagger$

\begin{tabular}{|c|c|c|c|c|}
\hline Variable & Estimate & $\mathrm{T}$ for $\mathrm{HO}$ : variable $=0$ & $\operatorname{Pr}>[\mathrm{T}]$ & SE of estimate \\
\hline Intercept & -99.57351026 & -1.58 & 0.1196 & $62 \cdot 90740202$ \\
\hline Age & -1.23263824 & -0.47 & 0.6393 & $2 \cdot 61454469$ \\
\hline \multicolumn{5}{|l|}{ Sex } \\
\hline Males & -0.65834022 & -0.19 & 0.8537 & 3.55304732 \\
\hline Females & 0.00000000 & - & - & - \\
\hline \multicolumn{5}{|l|}{ SES } \\
\hline High & -0.11289220 & -0.02 & 0.9806 & $4 \cdot 61696229$ \\
\hline Low & 0.00000000 & - & - & - \\
\hline Absolute BV & 0.02144944 & $1 \cdot 27$ & $0 \cdot 2113$ & 0.01694260 \\
\hline \multicolumn{5}{|l|}{ Undernutrition } \\
\hline Yes & $7 \cdot 12607668$ & $1 \cdot 21$ & $0 \cdot 2310$ & $5 \cdot 87892841$ \\
\hline No & 0.00000000 & - & - & - \\
\hline Child IQ & $1 \cdot 10419331$ & $7 \cdot 50$ & 0.0001 & $0 \cdot 14731203$ \\
\hline Paternal IQ & -0.03735763 & -0.23 & $0 \cdot 8220$ & $0 \cdot 16519179$ \\
\hline Maternal IQ & 0.28054932 & 1.86 & 0.0681 & 0.15054379 \\
\hline
\end{tabular}

SES, socio-economic stratum; BV, brain volume; IQ, intellectual quotient; T, Student's $t$ test; HO, null hypothesis; Pr, probability.

${ }^{*}$ For details of subjects and procedures, see pp. 82-83.

† Statistical Analysis Systems (SAS Institute, Cary, NC, USA), PROC GLM error type III.

$¥$ Model $r^{2}$ 0.848; Root MSE (standard deviation of the dependent variable (IQ)) 11.42507451; Model $F$ value $35.63, P<0.0001$. 
Table 6. Multiple regression analysis table between school-age children academic aptitude test score and most relevant variables (independent variables)* ${ }^{\star} \dagger$

\begin{tabular}{lrccc}
\hline Variable & Estimate & T for HO: variable $=0$ & $\operatorname{Pr}>[\mathrm{T}]$ & SE of estimate \\
\hline Intercept & -114.9461432 & -0.33 & 0.7395 & 343.6447760 \\
Age & -15.2824439 & -1.00 & 0.3210 & 15.2372264 \\
Sex & & & & \\
$\quad$ Males & 10.5749645 & 0.51 & 0.6096 & 20.5709801 \\
$\quad$ Females & 0.0000000 & - & - & - \\
SES & & & & 0.3334 \\
$\quad$ High & -23.3840539 & -0.98 & - & 23.9270288 \\
$\quad$ Low & 0.0000000 & - & - & - \\
Absolute BV & -0.0385714 & -0.39 & 0.6974 & 0.0985881 \\
Undernutrition & & & & \\
$\quad$ Yes & 21.2354040 & 0.52 & 0.6053 & 40.8105486 \\
$\quad$ No & 0.0000000 & - & - & - \\
Child IQ & 7.4201976 & 9.42 & 0.0001 & 0.7878331 \\
Paternal IQ & 1.5743873 & 1.84 & 0.0722 & 0.8559060 \\
Maternal IQ & 0.4822937 & 0.60 & 0.5482 & 0.7973744 \\
\hline
\end{tabular}

SES, socio-economic stratum; BV, brain volume; IQ, intellectual quotient; T, Student's $t$ test; HO, null hypothesis; Pr, probability.

${ }^{*}$ For details of subjects and procedures, see pp. 82-83.

† Statistical Analysis Systems (SAS Institute Inc., Cary, NC, USA), PROC GLM error type III.

$\ddagger$ Model $r^{2}$ 0.876; Root MSE (standard deviation of the dependent variable (IQ)) 59.67820833; Model $F$ value $41.37, P<0.0001$

attended private schools with very low school-year repetition rates; this could explain why the objectives pursued by the Ministry of Education are more likely to be successfully achieved by private schools (Ivanovic et al. 1989a, 1995b, 2001; Chile Ministerio de Educación Pública, 1996).

Maternal IQ, BV, and severe undernutrition during the first year of life were the independent variables with the greatest explanatory power in child IQ variance, without interaction with age, sex or SES. Maternal IQ probably is an important risk factor for undernutrition, decreased $\mathrm{HC}, \mathrm{BV}$, child IQ, SA and AAT. Mothers from the low SES and with the lowest schooling levels also have inadequate knowledge about nutrition and health (Ivanovic et al. 1997; Inzunza, 2001). On the other hand, mothers are the most important source of nutrition information for school-age children (Ivanovic et al. 1989b, 1991). The positive impact of maternal IQ may be related more to the quality of the stimulation of the child, which in conditions of poverty is strongly limited by both their lower schooling levels and IQ (Smith et al. 1996; Sandiford et al. 1997; Crandell \& Hobson, 1999). Although paternal IQ had a significant impact on child IQ, it is important to underline that schoolage children of the high SES with low IQ are probably conditioned by their maternal IQ that was significantly lower in that of mothers belonging to the low SES and whose children had high IQ. Children of the high SES with low IQ had not suffered from severe undernutrition in the first year of life but their BV, HC and SA were not different from their peers of the low SES with low IQ, of whom $64 \%$ had suffered from undernutrition in the first year of life. We do not have a clear explanation for these findings, although we can hypothesize that children of the high SES have been exposed to more favourable environmental conditions that favour the expression of their genetic potential; however, it seems that the maternal IQ is the most powerful determinant of child IQ. It is surprising that no significant differences were found between verbal and non-verbal IQ in mothers from high and low SES whose children had high IQ, and this confirms that the role of maternal IQ may be the critical determinant of child IQ (Bacharach \& Baumeister, 1998). Maternal schooling has been described as the most important socio-economic and socio-cultural variable associated with SA and child IQ (Ivanovic et al. 1995b, 2000a,b, 2001).

The IQ of school-age children is the only independent variable that explains most of the SA and AAT variance but this also summarises the effects of maternal IQ, BV and severe undernutrition during the first year of life; the significant impact of IQ on SA was observed in males and females and these results are in agreement with our previous findings (Ivanovic et al. 1989a, 2000c). Independently of SES, school-age children with low IQ obtained very low SA and AAT scores (below 450) that prevented them from applying to higher education and to better-paying jobs, to improve their quality of life, especially in the low SES.

In the present study, birth weight was associated with child IQ and several authors have reported that birth weight is associated with cognitive performance in young adult life (Bacharach \& Baumeister, 1998; Sorensen et al. 1999). The effect of very low birth weight on suboptimal HC and IQ has been reported by several authors (Hack \& Breslau, 1986; Ounsted et al. 1988; Hack et al. 1991; Teplin et al. 1991; Pryor et al. 1995; Botting et al. 1998; Strauss \& Dietz, 1998). Nevertheless, in the present study in spite of the finding that birth weight was positively and significantly associated with child IQ it did not help to explain IQ variance. Some authors have concluded that intrauterine growth retardation has a little impact on intelligence, except when associated with serious deficits in HC (Strauss \& Dietz, 1998). High-school graduates with the lowest IQ belonging to low SES exhibited the lowest birth weights. This could indicate that these children were already malnourished in utero. 
$\mathrm{HC}$ is the only anthropometric indicator of both nutritional background and brain development closely associated with BV (absolute or adjusted for height), child IQ, SA and AAT. Thus, anthropometric indicators of past nutrition are relevant in explaining differences in school-age IQ. Similar results were observed in quantitating the impact of the nutritional status upon SA and intellectual ability assessed through the Raven progressive matrices test, HC being the most important anthropometric indicator associated with this (Ivanovic et al. 1996, 2000a; Toro et al. 1998).

Positive and significant correlations between IQ and HC and brain size (absolute or adjusted for height) have been reported by many authors (Nelson \& Deutschberger, 1970; Van Valen, 1974; Fisch et al. 1976; Susanne, 1979; Rumsey \& Rapoport, 1983; Hack \& Breslau, 1986; Ounsted et al. 1988; Desch et al. 1990; Hack et al. 1991; Johnson, 1991; Willerman et al. 1991; Andreasen et al. 1993; Lynn, 1993; Jensen \& Johnson, 1994; Reiss et al. 1996; Botting et al. 1998; Strauss \& Dietz, 1998; Pennington et al. 2000; Ivanovic et al. 2000a,b,c; Rushton, 2000; Rushton \& Ankney, 1996, 2000; Vernon et al. 2000; Wickett et al. 2000) and in our present observations. As stated in a previous report, educational drop-out is related to $\mathrm{HC}$, but not to weight or height (Ivanovic et al. 1996). As in previous reports, from the results of the present study we can hypothesize again that children with suboptimal $\mathrm{HC}$ have some degree of alteration of brain development associated with the lowered IQ; differences in human brain size are relevant in explaining differences in IQ test performance (Ivanovic et al. 2000a,b).

Undernutrition remains the most important nutritional problem in developing countries, and at an early age affects the growth and development of children, especially in conditions of poverty, and has been associated with retarded brain growth and functional development that persists into adult life, such as in our present study (Stoch \& Smythe 1963, 1967, 1976; Winick \& Rosso, 1969a,b; Winick, 1975; Stoch et al. 1982; Hack \& Breslau, 1986; Hack et al. 1991; Udani, 1992; Cordero et al. 1993; Grantham-McGregor, 1995; Levitsky \& Strupp 1995; Brown \& Pollitt, 1996; Food and Agriculture Organization, 1996; Ivanovic, 1996; United Nations International Children's Emergency Fund, 1998; Ivanovic et al. 2000b; Leiva et al. 2001). However, these inter-relationships do not have a direct cause-effect relationship since complex interactions are established during the lifetime of the individuals. Therefore, malnutrition at an early age damages the brain or induces biochemical changes and the social and economic correlates of malnutrition are not the only explanation of the long-term effects of malnutrition on intelligence (Brown \& Pollitt, 1996; Pollitt et al. 2000). It is possible that other environmental and genetic factors, which were not quantitated, could affect birth weight, $\mathrm{HC}, \mathrm{BV}$, maternal IQ, child IQ and $\mathrm{SA}$; genetic factors have been described affecting both HC, BV and IQ (Weaver \& Cristian, 1980; Lynn \& Hattori, 1990; Casto et al. 1995; Bouchard, 1998; McGue \& Bouchard, 1998; Strauss \& Dietz, 1998). There will no doubt be many exciting attempts over the next several years to determine what it is about a larger brain that is beneficial to cognitive processing. In addition, attention will turn to what it is about intelligence that is predicted by BV. This aspect has been almost completely ignored in the literature (Wickett et al. 2000).

These present results confirm the hypotheses formulated for this study that: (1) independently of SES, high-school graduates with similar IQ have similar variables of nutritional status, brain development and SA; (2) past nutritional status, brain development, IQ and SA are strongly and significantly inter-related. These findings are relevant in explaining the complex interactions between variables that affect IQ and SA and emphasize the significant role of maternal IQ, BV and undernutrition at an early age.

\section{Acknowledgements}

The authors are very grateful to the Ministry of Education of Chile for all the facilities given to carry out this research; to Dr Oscar Brunser MD, for helpful comments and suggestions; to Ms Nora Díaz, for statistical assistance; to Mrs Viola Lyon for her secretarial assistance and to $\mathrm{Mr}$ Leopoldo Salgado for photographic work. Presented in part in the 16th International Congress of Nutrition, July 27August 1 1997, Montreal, Canada. Supported by Grant 1961032 from the National Fund for Scientific and Technologic Development (FONDECYT) and Grant 024/1997 from the University of Chile, Postgraduate Department.

\section{References}

Alvarez ML, Muzzo S \& Ivanovic D (1985) Escala para medición del nivel socioeconómico en el área de la salud (Scale for measurement of socio-economic level, in the health area). Revista Médica de Chile 113, 243-249.

Andreasen NC, Flaum M, Swayze V, O'Leary DS, Alliger R, Cohen G, Ehrhardt J \& Yuh WT (1993) Intelligence and brain structure in normal individuals. American Journal of Psychiatry 150, 130-134.

Bacharach VR \& Baumeister AA (1998) Effects of maternal intelligence, marital status, income, and home environment on cognitive development of low birthweight infants. Pediatric Psychology 23, 197-205.

Botting N, Powls A, Cooke RW \& Marlow N (1998) Cognitive and educational outcome of very low-birth weight children in early adolescence. Developmental Medicine and Child Neurology $\mathbf{4 0}$, $652-660$.

Bouchard TJ Jr (1998) Genetic and environmental influences on adult intelligence and special mental abilities. Human Biology 70, 257-279.

Broca P (1861) Sur le volume et al forme du cerveau suivant les individus et suivant les races (About the volume and shape of the brain through individuals and races). Bulletins et mémoires de la Société d'Anthropologie de Paris 2, 139-207, 301-321, 441446.

Brown L \& Pollitt E (1996) Malnutrition, poverty and intellectual development. Scientific American 274, 38-43.

Carter RL, Resnick MB, Ariet M, Shieh G \& Vonesh EF (1992) A random coefficient growth curve analysis of mental development in low-birth-weight infants. Statistics in Medicine 11, $243-256$.

Casto SD, DeFries JC \& Fulker DW (1995) Multivariate genetic 
analysis of Wechsler Intelligence Scale for Children - Revised (WISC-R) factors. Behavior Genetics 25, 25-32.

Chile Ministerio de Educación Pública (1996) Planes y Programas de Estudio para la Educación Media. Revista de Educación no. 225. Santiago: MINEDUC.

Cordero ME, Acuña E, Benveniste S, Prado R, Nuñez JA \& Colombo M (1993) Dendritic development in neocortex of infants with early postnatal life undernutrition. Pediatric Neurology 9, 457-464.

Crandell LE \& Hobson RP (1999) Individual differences in young children's IQ: a social-developmental perspective. Journal of Child Psychology and Psychiatry and Allied Disciplines 40, 455-464.

Desch LW, Anderson SK \& Snow JH (1990) Relationship of head circumference to measures of school performance. Clinical Pediatrics 29, 389-392.

Duncan GJ, Brooks-Gunn J \& Klebanov PK (1994) Economic deprivation and early childhood development. Child Development 65, 296-318.

Fisch RO, Bilek MK, Horrobin JM \& Chang PN (1976) Children with superior intelligence at 7 years of age: a prospective study of the influence of perinatal, medical and socioeconomic factors. American Journal of Diseases of Children 130, 481-487.

Food and Agriculture Organization (1996) Sexta Encuesta Alimentaria Mundial (Sixth World Food Survey). Rome: FAO.

Frisancho AR (1981) New norms of upper limb fat and muscle areas for assessment of nutritional status. American Journal of Clinical Nutrition 34, 2540-2545.

Frisancho AR (1990) Anthropometric Standards for Assessment of Growth and Nutritional status, Ann Arbor, MI: The University of Michigan Press.

Galton F (1888) Head growth in students at the University of Cambridge. Nature 38, 14-15.

Garrow JS (1981) Treat Obesity Seriously: A Clinical Manual, London: Churchill Livingstone.

Gecz J \& Mulley J (2000) Genes for cognitive function: developments on the X. Genome Research 10, 157-163.

Gibson R (1990) Principles of Nutritional Assessment, Oxford: Oxford University Press.

Grantham-McGregor S (1995) A review of studies of the effect of severe malnutrition on mental development. Journal of Nutrition 125, 2233S-2238S.

Guilford JP \& Fruchter B (1984) Estadística Aplicada a la Psicología y a la Educación (Fundamental statistics in psychology and education). México: McGraw Hill.

Hack M \& Breslau N (1986) Very low birth weight infants: effects of brain growth during infancy on intelligence quotient at 3 years of age. Pediatrics 77, 196-202.

Hack M, Breslau N, Weissman B, Aram D, Klein N \& Borawski E (1991) Effect of very low birth weight and subnormal head size on cognitive abilities at school age. New England Journal of Medicine 325, 231-237.

Inzunza N (2001) Interrelationship between nutrient intake and scholastic achievement of high school graduates from high and low socio-economic status: impact of mother's nutrition knowledge, MSC Thesis 2001, Loma Linda University, CA, USA.

Ivanovic D (1996) Does undernutrition during infancy inhibit brain growth and subsequent intellectual development? Nutrition 12, $568-571$.

Ivanovic D, Almagià A, Toro T, Castro C, Pérez H, Urrutia MS, Cervilla J, Bosch E \& Ivanovic R (2000c) Impacto del estado nutricional en el desarrollo cerebral, inteligencia y rendimiento escolar, en el marco de un enfoque multifactorial (Impact of nutritional status on brain development, intelligence and scholastic achievement in a multifactorial approach). $L a$ Educación (OEA) 44, 3-35.
Ivanovic D, Castro CG \& Ivanovic R (1997) Conocimientos alimentarios y nutricionales de madres de escolares de educación básica y media de diferentes niveles socioeconómicos (Food and nutrition knowledge of school-age children's mothers from elementary and high school from different socio-economic levels). Archivos Latinoamericanos de Nutrición 47, 248-255.

Ivanovic D, Forno H \& Ivanovic R (2001) Estudio de la capacidad intelectual (Test de Matrices Progresivas de Raven) en escolares de 5 a 18 años. II. Interrelaciones con factores socioeconómicos, socioculturales, familiares, de exposición a medios de comunicación de masas, demográficos y educacionales (Intellectual ability study (Raven Progressive Matrices Test) in school-age children from 5 to 18 years. II. Inter-relationships with socio-economic, cultural, familiar, mass media exposure, demographic and educational factors). Revista de Psicología General y Aplicada 54, 443-466.

Ivanovic D, Ivanovic R, Truffello I \& Buitrón C (1989a) Nutritional status and educational achievement of elementary first grade Chilean students. Nutrition Reports International 39, $163-175$.

Ivanovic D, Leiva B, Pérez $\mathrm{H}$, Inzunza $\mathrm{N}$, Almagià $\mathrm{A}$, Toro $\mathrm{T}$, Urrutia MS, Cervilla J \& Bosch E (2000b) Long-term effects of severe undernutrition during the first year of life on brain development and learning in Chilean high school graduates. Nutrition 16, 1056-1063.

Ivanovic D, Olivares M, Castro C \& Ivanovic R (1995a) Circunferencia craneana de escolares chilenos de 5 a 18 años (Head circumference in Chilean school children 5 to 18 years of age and socio-economic status). Región Metropolitana de Chile. 1986-1987, 1992. Revista Médica de Chile 123, 587-599.

Ivanovic D, Olivares M, Castro C \& Ivanovic R (1996) Nutrition and learning in Chilean school-age children: Chile's Metropolitan Region. Survey 1986-1987. Nutrition 12, 321-328.

Ivanovic R, Castro C \& Ivanovic D (1995b) No existe una teoría sobre el rendimiento escolar (It doesn't exist: a theory about scholastic achievement). Revista de Educación (Ministerio de Educación de Chile) 224, 40-45.

Ivanovic R, Forno H, Castro CG \& Ivanovic D (2000a) Intellectual ability and nutritional status assessed through anthropometric measurements of Chilean school-age children from different socioeconomic status. Ecology of Food and Nutrition 39, 1-25.

Ivanovic R, Olivares M \& Ivanovic D (1991) Sources of nutrition information of Chilean schoolers. Metropolitan Region. Chile Survey 1986-1987. Archivos Latinoamericanos de Nutrición 41, 527-538.

Ivanovic R, Truffello I, Buitrón C \& Ivanovic D (1989b) Educational factors influencing the nutritional learning of elementary first grade Chilean schoolers. Nutrition Reports International 39, 1161-1166.

Jelliffe DB (1966) The Assessment of the Nutritional Status of the Community, Geneva: WHO.

Jensen A \& Johnson F (1994) Race and sex differences in head size and IQ. Intelligence 18, 309-333.

Johnson FW (1991) Biological factors and psychometric intelligence: a review. Genetic, Social and General Psychology Monographs 117, 313-357.

Leiva B, Inzunza N, Pérez H, Castro V, Jansana JM, Toro T, Almagiá A, Navarro A, Urrutia MS, Cervilla J \& Ivanovic D (2001) Algunas consideraciones sobre el impacto de la desnutrición en el desarrollo cerebral, inteligencia y rendimiento escolar (Some considerations related to the impact of undernutrition on brain development, intelligence and scholastic achievement). Archivos Latinoamericanos de Nutrición 51, 6471.

Levitsky DA \& Strupp BJ (1995) Malnutrition and the brain: changing concepts, changing concerns. Journal of Nutrition 125, 2212S-2220S. 
Lynn R (1993) Brain size and intelligence in man: a correction to Peters. Canadian Journal of Experimental Psychology 47, 748-750.

Lynn R \& Hattori K (1990) The heritability of intelligence in Japan. Behavior Genetics 20, 545-546.

McGue M \& Bouchard TJ Jr (1998) Genetic and environmental influences on human behavioral differences. Annual Review of Neuroscience 21, 1-24.

Matano S \& Nakano Y (1998) Size comparison of the male and female human corpus callosum from autopsy samples. Zeitschrift fur Morphologie und Anthropologie 82, 67-73.

Melhuish EC, Lloyd E, Martin S \& Mooney A (1990) Type of childcare at 18 months. II. Relations with cognitive and language development. Journal of Child Psychology and Psychiatry and Allied Disciplines 31, 861-870.

Menkes JH (1995) Texbook of Child Neurology, Baltimore, MD: Williams and Wilkins.

Nelson KB \& Deutschberger J (1970) Head size at one year as a predictor of four-year IQ. Developmental Medicine and Child Neurology 12, 487-495.

Ounsted M, Moar VA \& Scott A (1988) Head circumference and developmental ability at the age of seven years. Acta Paediatrica Scandinavica 77, 374-379.

Pennington BF, Filipek PA, Lefly D, Chhabildas N, Kennedy DN, Simon JH, Filley CM, Galaburda A \& DeFries JC (2000) A twin MRI study of size variations in human brain. Journal of Cognitive Neuroscience 12, 223-232.

Peters M, Jancke L, Staiger JF, Schlaug G, Huang Y \& Stenmetz H (1998) Unsolved problems in comparing brain sizes in homo sapiens. Brain and Cognition 37, 254-285.

Pollitt E, Jahari A \& Walka H (2000) A developmental view of the effects of an energy and micronutrient supplement in undernourished children in Indonesia. European Journal of Clinical Nutrition 54, S107-S113.

Pryor J, Silva PA \& Brooke M (1995) Growth, development and behaviour in adolescents born small-for-gestational-age. Journal of Paediatrics and Child Health 31, 403-407.

Reiss Al, Abrams MT, Singer HS, Ross JL \& Denckla MB (1996) Brain development, gender and IQ in children. A volumetric imaging study. Brain 119, 1763-1774.

Roche AF, Mukherjee D, Guo S \& Moore W (1987) Head circumference reference data: birth to 18 years. Pediatrics $\mathbf{7 9}$, 706-712.

Rumsey JM \& Rapoport JL (1983) Assessing behavioral and cognitive effects of diet in pediatric populations. In Nutrition and the Brain, pp. 101-161 [RJ Wurtman and JJ Wurtman, editors]. New York, NY: Raven Press.

Rushton JP (2000) Race, Evolution, and Behavior: A Life-history Perspective, 2nd special abridged ed., Port Huron, MI: Charles Darwin Research Institute.

Rushton JP \& Ankney CD (1996) Brain size and cognitive ability: Correlations with age, sex, social class, and race. Psychonomic Bulletin and Review 3, 21-36.

Rushton JP \& Ankney CD (2000) Size matters: A review and new analyses of racial differences in cranial capacity and intelligence that refute Kamin and Omari. Personality and Individual Differences 29, 591-620.

Sandiford P, Cassel J, Sanchez G \& Coldham C (1997) Does intelligence account for the link between maternal literacy and child survival? Social Science and Medicine 45, 1231-1239.

Schoenemann PT, Budinger T, Sarich V \& Wang W (2000) Brain size does not predict general cognitive ability within families. Proceedings of the National Academy of Science, USA 97, $4932-4937$.

Smith KE, Landry SH, Swank PR, Baldwin CD, Denson SE \& Wildin S (1996) The relation of medical risk and maternal stimulation with preterm infants' development of cognitive, language and daily living skills. Journal of Child Psychology and Psychiatry and Allied Disciplines 37, 855-864.

Sorensen HT, Sabroe S, Olsen J, Rothman KJ, Gillman MW \& Fisher P (1999) Birth weight as a predictor of young men's intelligence. A historical cohort study. Ugeskrift for Laeger 161, $791-793$.

Stoch MB \& Smythe PM (1963) Does undernutrition during infancy inhibit brain growth and subsequent intellectual development? Archives of Disease in Childhood 38, 546-552.

Stoch MB \& Smythe PM (1967) The effect of undernutrition during infancy on subsequent brain growth and intellectual development. South African Medical Journal 41, 1027-1030.

Stoch MB \& Smythe PM (1976) 15-year developmental study on effects of severe undernutrition during infancy on subsequent physical growth and intellectual functioning. Archives of Disease in Childhood 51, 327-336.

Stoch MB, Smythe PM, Moodie AD \& Bradshaw D (1982) Psychosocial outcome and CT findings after gross undernourishment during infancy: a 20-year developmental study. Developmental Medicine and Child Neurology 24, 419-436.

Strauss RS \& Dietz WH (1998) Growth and development of term children born with low birth weight: effects of genetic and environmental factors. Journal of Pediatrics 133, 67-72.

Susanne C (1979) On the relationship between psychometric and anthropometric traits. American Journal of Physical Anthropology 51, 421-424.

Teplin SW, Burchinal M, Johnson-Martin N, Humphry RA \& Kraybill EN (1991) Neurodevelopmental, health and growth status at age 6 years of children with birth weights less than 1001 grams. Journal of Pediatrics 118, 768-777.

Toro T, Almagià A \& Ivanovic D (1998) Evaluación antropométrica y rendimiento escolar en estudiantes de educación media de Valparaíso Chile (Anthropometric assessment and school achievement in school-age children from high school in Valparaiso, Chile). Archivos Latinoamericanos de Nutrición 48, 201-209.

Tramo MJ, Loftus WC, Stukel TA, Green RL, Weaver JB \& Gazzaniga MS (1998) Brain size, head size, and intelligence in monozygotic twins. Neurology 50, 1246-1252.

Udani PM (1992) Protein energy malnutrition (PEM), brain and various facets of child development. Indian Journal of Pediatrics 59, 165-186.

United Nations International Children's Fund (1994) Una Propuesta de' Clasificación de las Comunas del País Según la situación de la Infancia (A proposal to classify Chilean districts by infancy situation). Santiago: UNICEF.

United Nations International Children's Fund (1998) Estado Mundial de la Infancia (Infancy World Situation). New York, NY: UNICEF.

Van Valen L (1974) Brain size and intelligence in man. American Journal of Physical Anthropology 40, 417-424.

Vernon PA, Wickett JC, Bazana PG \& Stelmack RM (2000) The neuropsychology and psychophysiology of human intelligence. In Handbook of Intelligence, [RJ Sternberg, editor]. New York, NY: Cambridge University Press.

Weaver DD \& Cristian JC (1980) Familial variation of head size and adjustment for parental head circumference. Journal of Pediatrics 96, 990-994.

Wechsler D (1981) Manual for the Wechsler Adult Intelligence Scale - Revised, New York, NY: Psychological Corporation.

Wickett JC, Vernon PA \& Lee DH (2000) Relationships between factors of intelligence and brain volume. Personality and Individual Differences 29, 1095-1122.

Willerman L, Schultz R, Rutledge JN \& Bigler ED (1991) In vivo brain size and intelligence. Intelligence 15, 223-228. 
Winick M \& Rosso P (1969a) Head circumference and cellular growth of the brain in normal and marasmic children. Journal of Pediatrics 74, 774-778.

Winick M \& Rosso P (1969b) The effect of severe early malnutrition on cellular growth of human brain. Pediatric Research 3, 181-184.
Winick M (1975) Nutrition and brain development. In Nutrition and mental functions, pp. 65-73 [G Serban, editor]. New York, NY: Plenum Press.

World Health Organization (1980) Measurement of the Nutritional Impact of Supplementation Food Programs to Vulnerable Groups. FAP/79.1, Geneva: WHO. 